\title{
4. Lo absoluto del saber absoluto*
}

El propósito de este escrito es relativamente sencillo: busca examinar el sentido que le otorga Hegel a su concepto de "saber absoluto", con el cual titula el capítulo final de la Fenomenología del espiritu, analizándolo desde una doble perspectiva. Por una parte, como respuesta a la búsqueda, suscitada por Descartes, de un saber que se halle exento de toda posible duda; "saber absoluto", en este sentido, vendría a significar un saber que se fundamenta a sí mismo, un saber que no necesita de una ulterior justificación. Absoluto tiene, entonces, un sentido claramente etimológico: se trata de un saber que no depende a su vez de otro saber, que se halla suelto (ab-solutum), es decir, que a la vez que constituye el fundamento de todo otro saber, él mismo es, en alguna forma, su propio fundamento.

Pero, por otra parte, "saber absoluto" tiene también un sentido religioso, ya que el capítulo desempeña la función de síntesis dialéctica de los dos capítulos anteriores titulados, respectivamente, "Espíritu" y "Religión". El primero, el espíritu, dicho en términos muy generales, corresponde al proceso de culturización (Bildung) de Europa a partir del mundo griego, y el segundo,

* Una primera versión de este texto fue publicada en Eidos, revista de filosofía de la Universidad del Norte, Barranquilla, 11, 2009, pp. 10-34. 
al desarrollo de la religión como la autoconciencia propia de cada cultura, como la forma en que cada cultura plasma sus más elevados ideales. Desde esta perspectiva, el "saber absoluto" corresponde a la puerta de entrada a la filosofía o al sistema filosófico; sistema que debería desarrollarse luego de la Fenomenología, y al cual esta servía de introducción. En este saber, la religión es superada, en el sentido hegeliano de la palabra (Aufhebung), es decir, suprimida a la vez que elevada y conservada. En otras palabras, en ese saber la religión llega a su culminación al elevarse por encima de sí misma, y al hallar, en esa nueva forma, su verdadera realización, es decir, el sentido pleno de su esencia. Esa superación lleva a cabo, según la dinámica del movimiento dialéctico, la síntesis entre espíritu y religión, es decir, que la trascendencia que caracteriza a lo religioso se integra con la inmanencia propia de lo cultural. Veremos en qué sentido se lleva a cabo dicha síntesis.

Ahora bien, el saber absoluto como última figura de la conciencia no ha dejado de suscitar cuestionamientos por parte de los comentaristas del pensamiento hegeliano, al ver en ella una pretensión que resulta a todas luces exorbitante: la pretensión de un "saber absoluto" vendría a significar, por una parte, que la filosofía habría llegado a su culminación, al haber alcanzado un conocimiento situado más allá de toda crítica; y, por otra, que la religión habría llegado a su fin, al haber sido absorbida plenamente por el saber especulativo. En uno y otro caso cabe muy bien pensar en un claro exceso especulativo por parte de Hegel.

Una presentación general de esta clase de críticas podemos encontrarla en el excelente artículo de Luis Eduardo Gama, titulado "El camino de la experiencia: la Fenomenología del espiritu", donde, luego de hacernos una muy clara exposición de la obra y de resaltar el papel central que juega la experiencia en el pensamiento hegeliano, se refiere al final del movimiento de la conciencia, es decir, al saber absoluto. Señala cómo se han presentado dos interpretaciones de esta última figura de la conciencia. Mientras que para algunos significa "una prueba del carácter cerrado del sistema hegeliano, impermeable a formas de experiencia históricas distintas a las que Hegel analizó"; otros, en cambio, señalan que "no puede haber un cierre definitivo o un telos sustancial 
del sistema, en una filosofía que insiste de una manera tan radical en la autonomía del pensamiento" (Gama, 2008, p. 165).

Es cierto que Gama no toma partido por ninguna de las dos interpretaciones, aunque señala:

El agudo análisis hegeliano de la experiencia humana no pierde en profundidad o pertinencia por el hecho de que quizás Hegel, movido por el prejuicio metafísico de una razón absoluta totalizadora, hubiese hecho concluir la experiencia en un punto determinado (Gama, 2008, p. 165).

Y en términos parecidos se expresa Heidegger, cuando, al describir la conflictiva relación entre Hegel y Schelling, y el disgusto de este último por la crítica hecha a su pensamiento en el texto de la Fenomenología, nos dice:

Hegel, por el contrario, ha reconocido siempre las grandes ejecutorias del amigo más joven, que una vez había llegado a ser famoso antes que él. Esto tampoco ha debido costarle mucho, años después, pues él se sabía en posesión del sistema absoluto del saber absoluto, y desde esa posición de todas las posiciones podría dejar valer también a aquellos que él tenía por secundarios (Heidegger 1985, p. 15).

En otras palabras, Hegel habría llegado a creerse en posesión de un saber que estaría por encima de todos los saberes y que, por su carácter "absoluto", se hallaría exento de toda posible crítica, a la vez que estaría en condición de criticar todo otro saber y señalarle su lugar relativo dentro de aquel. Las experiencias humanas habrían llegado a su fin, y con ellas la filosofía, de modo que a los pensadores venideros solo les cabría la suerte de repetir una y otra vez lo ya logrado. El sistema de pensamiento que se desarrollaría a continuación de la Fenomenología vendría a ser así el sistema por excelencia, un saber de lo real que nunca podría ser superado en ninguno de los sentidos de este término. 
Sin embargo, es claro que esa interpretación del significado de "saber absoluto" no puede menos que contradecir de manera flagrante no solo la insistencia hegeliana en la autonomía del pensamiento, sino igualmente y sobre todo el carácter histórico de este. Tal vez ningún filósofo anterior a él haya tenido tan clara conciencia de que su pensamiento se hallaba radicalmente condicionado por el tiempo histórico de su aparición. Mal podría él pensar en un final de este que clausurara toda apertura hacia un futuro impredecible.

Creo que una lectura serena del pensamiento hegeliano nos permite señalar que el sentido de un saber absoluto solo puede ser el de un saber que ha alcanzado la conciencia humana en un momento dado de su desarrollo histórico, y que constituye un hito imprescindible en ese mismo desarrollo; hito que a la vez que corona los esfuerzos del pasado, establece un punto de partida para los desarrollos posteriores. Hegel, como muchos de sus contemporáneos, estaba convencido de que en su momento histórico se hallaba asistiendo a la terminación de un largo periodo cuyos orígenes se situaban en Jerusalén y en Atenas. Ya no se trataba de una peripecia más en la ya larga historia de Europa, sino de la ejecución de su acto final. ¿Qué vendría después? Es algo que Hegel se negaba a predecir, convencido, como estaba, de que la filosofía solo podía mirar hacia el pasado, ya que al buscar la verdad sin concesiones, solo podía hallarla allí donde ya la historia se había consumado. Lo que ha sucedido es verdadero sin remedio y no da lugar para predicciones o suposiciones, sino que está ahí para ser comprendido; mientras que el porvenir pasa de manera inexorable por la voluntad de los seres humanos, de modo que su resultado viene a ser por completo impredecible para la razón. Esta solo puede saber que, una vez que haya acontecido, ese futuro será igualmente comprensible.

Es en este sentido, y solo en este, como Hegel puede hablar de manera coherente de un final de la historia y, correlativamente, de un saber absoluto. Al hacer el balance de la historia pasada, a la cual puede contemplar desde un mirador excepcional como el de la Revolución francesa, cuya significación, a los ojos de Hegel, marca el comienzo del fin de la historia europea, él cree poder señalar un nuevo saber alcanzado por la conciencia a lo largo de ese recorrido: un saber para el cual la realidad no puede ser comprendida sino 
como autoconciencia, para el cual toda objetividad debe entenderse como un momento de la subjetividad como tal.

Ahora bien, un vez que hemos formulado así el objeto de dicho saber, si bien es cierto que parece escapar a los excesos en que parecía caer, no deja, sin embargo, de causar honda extrañeza. ¿Cómo así que la realidad debe ser entendida como autoconciencia? ¿Acaso la realidad no es precisamente, como lo había señalado muy bien Descartes, lo otro del sujeto, lo otro de la autoconciencia? ¿Cómo pretende Hegel dar un salto desde el sujeto hasta la realidad sin ningún intermediario, cuando Descartes, para superar ese abismo que él mismo había labrado con su duda radical, se había visto obligado a buscar apoyo en la veracidad divina, sin lograrlo? (AT VII 34 y ss.). Recordemos su prueba de la existencia de Dios, y la certera objeción presentada por el teólogo Antoine Arnauld, el llamado "círculo cartesiano" o "círculo de Arnauld" (ver Hoyos, 2001).

Es cierto que para entender todo el significado de la tesis hegeliana acerca de un saber absoluto haría falta recorrer con paciencia el largo camino que nos presenta la Fenomenología, desde la experiencia ingenua de un saber inmediato hasta la comprensión especulativa de su radical inversión en la cual consiste ese saber absoluto. Sin embargo, ello no debe ser óbice para que intentemos comprender al menos los rasgos generales de la tesis que Hegel se propuso sustentar, a saber, que la realidad tiene la forma de la subjetividad, de modo que entre el sujeto que piensa y la realidad pensada no existe ningún abismo, sino una verdadera identidad dialéctica, es decir, una identidad que no descarta la diferencia, sino que la asume como su propio elemento. Es precisamente por ese acto de ruptura o de separación que establece la conciencia gracias a su acto reflexivo, en virtud del cual ella se pone como lo otro de la realidad y pone la realidad como lo otro de sí, que esa misma realidad despliega su forma de autoconciencia.

Dicho en otros términos, no se trata propiamente, como pensó Descartes, de que la conciencia trate de alcanzar un mundo que le es ajeno precisamente porque ella misma lo apartó de sí mediante su reflexión; se trata de que el 
sujeto, al tomar conciencia del sentido de su acto reflexivo gracias al cual él se pone a sí mismo y pone la realidad como su otro, comprenda que es en él y por él como la realidad está tomando conciencia de sí. El saber especulativo no es un esfuerzo de un sujeto por apropiarse de un objeto que le es ajeno, sino el acto mediante el cual la realidad misma, en el sujeto y por el sujeto, toma conciencia de sí y expone la forma de su propio devenir. Este es el sentido del saber "especulativo", es decir, especular o reflexivo.

Para comprender mejor esto tendremos que precisar algunos conceptos y tratar de encadenarlos de manera coherente, con lo cual analizaremos el primer sentido del "saber absoluto", es decir, su sentido epistemológico u ontológico. En este primer sentido, saber absoluto significa un saber fundamental para el cual lo que es tiene la forma del pensamiento, en otras palabras, para el cual existe una identidad diferenciada entre el sujeto que conoce y el objeto conocido, a la manera de un espejo.

Como lo hemos señalado antes, Hegel desarrolla su argumentación tomando como punto de partida nuestro saber espontáneo, inmediato, ingenuo, al que llama "certeza sensible". Se trata de la convicción espontánea que tiene la conciencia en el momento mismo de confrontar la realidad; ella considera que esa realidad se halla compuesta de entidades singulares únicas e irrepetibles, de modo que cada una es ella misma y nada más, y su propia afirmación implica la negación de todo otro. Sin embargo, al analizar este pretendido saber, hallamos que las cosas solo pueden ser dichas, solo podemos referirnos a ellas, en la medida en que se muestran como poseedoras de cualidades comunes, de determinaciones que expresamos con términos de carácter universal: mesa, silla, madera, etc. Expresado en términos hegelianos, al reflexionar sobre la realidad, esta a su vez se reflexiona sobre sí misma al diferenciar en sí un núcleo interior, al que llamamos sustancia, y una serie de determinaciones o cualificaciones que constituyen sus predicados. Las cosas se muestran así como verdaderos singulares universalizados, es decir, son cosas singulares que tienen a su vez un doble carácter universal. Por una parte, su núcleo interior o "sustancia", aquello que las constituye como un "esto", es en realidad algo abstracto, igual en todas las cosas por su misma indeterminación: todas 
las cosas son un "esto". Y, por otra parte, sus cualidades o predicados, con los cuales se caracteriza ese "esto", son a su vez determinaciones de carácter universal compartidas por diversos objetos posibles: "esto es una silla", "esto es una mesa".

Estos universales singularizados, o singulares universalizados, son los que conocemos con el término genérico de cosas. Ya no se trata de singulares únicos, sino de ejemplares de diversas clases o conjuntos: mesas, sillas, etc. $\mathrm{Al}$ acto mediante el cual la conciencia capta ya no singulares únicos, sino singulares universalizados, lo llama Hegel percepción. Pero la percepción, como la certeza sensible, tiene también su propia contradicción. Cuando examinamos esas cosas, nos percatamos de que en realidad implican una contradicción profunda: si sus cualidades son predicadas de un esto (por ejemplo, esto es una silla), ¿qué viene a ser propiamente ese esto? Como lo había mostrado con mucha razón Hume, ese esto no es en realidad nada más que una proyección del sujeto que conoce, mediante la cual establece un sujeto virtual de las determinaciones o predicados que se le atribuyen. La pretendida sustancia de las cosas, o se reduce a sus determinaciones universales, o desaparece cuando se la considera como distinta de ellas. De ahí que la realidad deba ser concebida por el pensamiento científico no como compuesta de cosas, de entidades independientes, sino de fuerzas que se entrecruzan y entrechocan. A esa nueva perspectiva de la conciencia, que considera el mundo o la realidad ya no como un conjunto de singulares únicos e irrepetibles, ni tampoco como un entramado de cosas interrelacionadas pero estables, sino como un completo "juego de fuerzas", la llama Hegel entendimiento y corresponde al conocimiento que solemos llamar científico.

Una vez que la realidad — que nos parecía en un primer momento sólida, y nos lo sigue pareciendo cuando no reflexionamos sobre ella - se nos ha desleído entre las manos al tratar de comprenderla, y se nos ha convertido en un indetenible juego de fuerzas contrapuestas y de una infinita complejidad, Hegel considera que la conciencia se halla preparada para dar un giro radical en su manera de confrontar el mundo; porque una realidad que se muestra como puro movimiento, en la cual nada es consistente ni estable, 
sino radicalmente pasajero, no puede por sí misma llegar a tener sentido, ya que su precariedad ontológica se reduce a un mero presente inasible. Sentido solo podrá llegar a tenerlo para un sujeto que, al tener conciencia de su propia permanencia a través del tiempo, es capaz de hacer que surja un sentido en esa realidad radicalmente pasajera.

Examinemos esto con un poco más de atención. Si la realidad es movimiento y este solo existe en el mero presente, resulta claro que su consistencia ontológica es, por decirlo de alguna manera, mínima. Una realidad pasajera, cuya existencia se reduce a la mera exigüidad del presente, no alcanza por sí misma a tener sentido alguno, porque su pasado ya no es y su futuro no es todavía. Para que surja un sentido será necesario que su pasado y su futuro sean, por decirlo así, recuperados, recogidos y proyectados, de modo que sobre ese trasfondo surja el sentido de dicho pasar. Y es esto lo que solo puede acontecer gracias a un sujeto que tenga conciencia. No es que la realidad no tenga sentido, y que la conciencia se lo otorgue, sino que solo puede llegar a tenerlo para una conciencia que lo haga real; en la realidad misma, dicho sentido solo existe de manera potencial, como una posibilidad que, gracias a la conciencia, se vuelve efectiva.

En forma muy resumida he presentado las tres primeras figuras de la conciencia, o las tres primeras "experiencias" que realiza la conciencia en su intento por comprender la realidad. Como lo he indicado, la conciencia primero ve dicha realidad como un conjunto de singulares únicos e irrepetibles, y a esta forma de conciencia la llama Hegel certeza sensible; luego la comprende como compuesta de singulares que pertenecen a diversas clases, y a esta figura la llama percepción; y finalmente la realidad se diluye en un mero juego de fuerzas ante la mirada de una conciencia a la que Hegel denomina entendimiento. Pues bien, comprender la necesidad de ese proceso, entender que la realidad no puede menos que desleírse entre nuestras manos cuando intentamos comprenderla, nos permite dar el primer paso hacia lo que habrá de ser ese saber absoluto que tratamos de examinar. 
Es importante, cuando leemos la Fenomenología, que no perdamos de vista esta primera tríada de experiencias, porque constituye el punto de partida que marca todo el desarrollo posterior. Oigamos al mismo Hegel, cuando busca indicarnos el paso de la conciencia a la autoconciencia:

El avance necesario de las anteriores figuras de la conciencia para las cuales lo verdadero era una cosa, algo otro que ellas mismas, expresa precisamente no solo que la conciencia de la cosa solo es posible para una autoconciencia, sino que únicamente esta última es la verdad de aquellas figuras $(P h .102)^{1}$.

Para comprender todo el sentido de esta observación, debemos tener en cuenta algo que Hegel nos había señalado unas líneas antes. Al incontenible fluir de lo real lo entiende Hegel como el verdadero infinito o la verdadera infinitud, ya que implica la inmediata superación de todo límite, de toda determinación. Y nos dice:

Es cierto que la infinitud, o esa absoluta inquietud del puro moverse a sí mismo, el que aquello que sea determinado de alguna manera, por ejemplo, como ser, sea más bien lo contrario de esa determinación, había sido ya el alma de todo lo anterior, pero únicamente en lo interior ha surgido ella misma libremente $(P h .100)$.

Notemos, de paso, este concepto de infinitud, que no es lo inmensamente grande, lo inabarcable cuantitativamente, sino aquello que por su propia naturaleza niega todo límite, aquello que solo puede ser pensado de manera cualitativa. El absoluto movimiento es el verdadero infinito como puro moverse a sí mismo, porque pone las diferencias precisamente para negarlas.

1 Se cita la Fenomenología por la paginación de la edición de W. Bonsiepen y R. Heede (1980), que se encuentra igualmente en la traducción al español de Antonio Gómez (2010). 
Ahora bien, la experiencia que hace la conciencia humana al buscar comprender la realidad la ha llevado inexorablemente a que esta se le muestre como un incontenible devenir, una realidad que bien podemos llamar heracliteana, en la cual todo fluye (panta rei), y que el entendimiento busca explicar mediante leyes. Pero esas leyes, mediante las cuales las ciencias nos explican la realidad, no pueden menos de resultar desconcertantes; porque las leyes en verdad no hacen otra cosa que transformar aquello que es puro movimiento en entidades fijas y discretas que presentan formas intemporales. En otras palabras, convierten lo totalmente fluido y circunstancial en algo fijo y permanente. La diferencia universal, es decir, esa "absoluta inquietud", dice Hegel,

es expresada en la ley como la imagen permanente del inestable fenómeno. El mundo suprasensible es así un reino tranquilo de leyes, allende, es cierto, del mundo percibido, porque este presenta la ley únicamente a través del permanente cambio, pero [la ley] está igualmente presente así en él, y es su copia inmediata quieta (Ph. 91).

Si las leyes vienen a ser la verdad de un mundo en completo movimiento, ellas se muestran como entidades inmóviles, intemporales, como un "reino tranquilo de leyes". Pues bien, señala Hegel más adelante: "El explicar del entendimiento hace únicamente por el momento la descripción de lo que es la autoconciencia" (Ph. 100-101). La quietud de las leyes no es otra que la quietud de la conciencia gracias a la cual ese devenir incontenible adquiere significación.

Entender esto es de la mayor importancia, porque nos hace ver cómo esas leyes que, por decirlo así, fijan la realidad fluyente, la atrapan de manera consistente, haciéndonos ver la forma permanente que rige su mismo devenir; esas leyes, digo, son así la manifestación objetiva de lo que es la autoconciencia, es decir, "una certeza - dice Hegel — que es igual a su verdad, porque la certeza se es ella misma su objeto, y la conciencia se es ella misma lo verdadero" (Ph. 103). 
Precisemos esto un poco más. Si la realidad es un incesante fluir incontenible, solo podrá adquirir consistencia y manifestar de esa manera el sentido de dicho fluir si disponemos de un punto de vista fijo, de un referente que se mantenga idéntico dentro del flujo mismo de ese devenir. Y ese punto fijo es precisamente la autoconciencia que, sabiéndose a sí misma como idéntica, sirve de punto de referencia para poder determinar el sentido de la realidad que fluye.

A ello precisamente se refería Kant con el concepto de "apercepción trascendental". Recordémoslo:

A toda necesidad subyace siempre una condición trascendental. Por lo tanto, tiene que hallarse un fundamento trascendental de la unidad de la conciencia en la síntesis de la pluralidad de todas nuestras intuiciones, por consiguiente, también de los conceptos de objetos [Objecte] en general y, consecuentemente, también de todos los objetos de la experiencia. Sin este fundamento sería imposible pensar objeto alguno de nuestras intuiciones, pues este no es más que aquello de lo cual el concepto expresa tal necesidad de síntesis ( $\mathrm{KrV}$ A106).

Y remata en el párrafo siguiente: "Esta condición originaria y trascendental no es más que la apercepción trascendental"2.

Ahora bien, si la conciencia que lleva a cabo las experiencias en la Fenomenología ha visto cómo la realidad objetiva se le deshacía entre las manos, esto la obliga a volver sobre sí para buscar en ella ese punto de apoyo del cual carece. De ahí que de esta conciencia de sí o autoconciencia nos diga Hegel:

2 Hemos seguido la traducción de la Deducción trascendental de los conceptos puros del entendimiento, versión A, elaborada por Pedro Stepanenko (Ideas y Valores, Bogotá, 127, abril de 2005, pp. 99-126). 
Es la reflexión a partir del ser del mundo sensible y percibido, y esencialmente el retorno desde el ser-otro. Como autoconciencia es movimiento; pero en cuanto que diferencia de sí únicamente a sí misma como sí misma, entonces la diferencia es para ella inmediatamente superada como un ser-otro; la diferencia no es, y ella es solo la tautología carente de movimiento del: yo soy yo; en tanto que para ella la diferencia no tenga también la figura del ser, ella no es autoconciencia $(P h .104)$.

En aras de la brevedad, y para no recargar demasiado nuestra reflexión, evitaré entrar en una serie de detalles que, si bien son de gran importancia para la comprensión de la propuesta filosófica de Hegel, nos llevarían lejos de nuestro propósito. Solo resalto de esta cita dos puntos. El primero, que a la autoconciencia se llega a partir de la conciencia, como un retorno desde la exterioridad a la interioridad, pero precisamente la comprendemos como la condición de la conciencia. En otras palabras, llegamos a conocer la autoconciencia o a nosotros mismos como resultado de la conciencia, de conocer lo otro como otro. Pero nos damos cuenta de que esa autoconciencia era en realidad la condición de posibilidad de la conciencia. Llego a saber de mí porque sé de lo otro, pero descubro que mi saber de mí era en realidad condición de posibilidad del saber de lo otro. Y el segundo punto es que la autoconciencia es movimiento, dinamicidad, pero como diferencia que se niega para ser en realidad identidad: se sabe como identidad en el seno mismo de su indetenible devenir.

Creo que, con lo señalado hasta aquí, cabe entender, al menos de manera inicial, que la tesis según la cual la realidad debe ser pensada a la luz de la autoconciencia comienza a tener algún sentido. Sin la autoconciencia no resulta posible que la realidad adquiera significado alguno. Más aún, la solidez que los objetos de nuestro conocimiento parecen tener la reciben de la identidad que caracteriza a la autoconciencia. Pero Hegel pretende algo más, a saber, que esa realidad tiene en sí misma la estructura del yo, la estructura de la autoconciencia. 
Y para entenderlo hay que introducir el concepto de "vida" como resultado de las consideraciones que acabamos de hacer, concepto que exige tener en cuenta cómo la realidad, que solo es comprensible mediante la autoconciencia en su carácter de lo otro de ella, tiene en sí misma una cierta consistencia:

Ahora bien — dice Hegel—, el objeto, que para la autoconciencia es lo negativo, para nosotros o en sí ha retornado por su parte dentro de sí, así como la conciencia por la suya. Mediante esta reflexión dentro de sí él ha llegado a ser vida (Ph. 104).

En otras palabras, la realidad pasajera es vida en la medida que en ella misma hay una cierta permanencia, una cierta continuidad. Pero, ¿de qué permanencia se trata? Precisamente de la permanencia de la vida: la realidad es pensada, entonces, como una realidad orgánica, viviente. Ahora bien, ¿cómo define Hegel la vida? Tenemos aquí una de esas formulaciones típicamente hegelianas que suelen repetirse hasta el cansancio, pero a las que pocos parecen prestarle verdadera atención:

A esta infinitud simple o al concepto absoluto hay que llamarlo la esencia simple de la vida, el alma del mundo, la sangre universal, que siendo omnipresente no se empaña ni se ve interrumpida por ninguna diferencia, sino que es más bien todas las diferencias, así como su ser suprimidas, que palpita por lo tanto dentro de sí sin moverse y tiembla dentro de sí sin estar inquieta (Ph. 99).

Y pocas páginas más adelante, cuando avanza en el análisis de lo que significa la autoconciencia, nos dice:

La determinación de la vida, tal como se deriva del concepto o el resultado universal con el cual ingresamos a esta esfera, es suficiente para caracterizarla, sin que haya que desarrollar más su naturaleza a partir de allí; su círculo se cierra en los 
siguientes momentos. La esencia es la infinitud como el haber-sido-superadas todas las diferencias, el puro movimiento axial, la quietud de sí misma como de la infinitud absolutamente-inquieta; la autosuficiencia en la que las diferencias del movimiento se han disuelto; la esencia simple del tiempo que, en esta igualdad-consigo, tiene la sólida figura del espacio $(\mathrm{Ph}$. 105).

Más que analizar estas formulaciones, es conveniente "rumiarlas", degustarlas, examinarlas con atención, ya que, en un lenguaje realmente paradójico, buscan que apreciemos lo que significa eso que solemos llamar el misterio de la vida.

En su libro La ontología de Hegel y la teoría de la historicidad, nos explicaba H. Marcuse que la vida como movilidad es infinita, "porque nunca se acaba, nunca se agota, sino que se mantiene y es asumida en la unidad de lo viviente" (260). Y un poco más adelante añade:

[La vida] no es un ente cualquiera entre otros, es más bien un medium, un medio para todo ente, en el cual todo ente es mediado, de tal manera que solo acontece en esa mediación; una "fluidez" que acarrea a todo ente, lo empapa y lo penetra todo, y como tal fluidez constituye precisamente la "sustancia de lo entitativo": aquello por lo cual lo ente viene a tener "consistencia”. Y como tal fluidez universal, la vida no se agota, sino que permanece infinitamente igual a sí misma como auto-consistencia infinita (261-262).

Creo que, una vez establecido este concepto de vida como el movimiento que permanece siempre igual a sí mismo mediante la diferencia de sus momentos, podemos ahora dar un salto hasta el final de la Fenomenología, para entender la forma como el texto nos introduce en el saber absoluto. 
Y para ello conviene tener en cuenta los tres grandes momentos que desarrolla ese mismo capítulo final bajo el título de "Saber absoluto"3.

En primer lugar, se analiza "el contenido simple del sí-mismo que se muestra como el ser"; en otras palabras, se busca mostrar cómo el verdadero concepto de ser, de aquello que es en cuanto que es, tiene el carácter del sí mismo, de la autoconciencia. Luego se expone "la ciencia [la filosofía] como el autoconcebirse del sí-mismo", es decir, que el aforismo del templo de Apolo en Delfos, "conócete a ti mismo" (gnothi seauton), viene a ser, entonces, el verdadero conocimiento de lo que es. Y finalmente se muestra "el espíritu comprendido en su retorno a la inmediatez que está-ahí", es decir, que el saber absoluto no es otro que el modo de entenderse el sentido común, pero una vez que ha comprendido a fondo su verdadero carácter de fundamento. Para mi propósito, solo examinaré la primera parte, aquella en la cual se nos muestra cómo el verdadero ser debe comprenderse como autoconciencia, que viene a ser precisamente la tesis que he señalado al comenzar este escrito, y que no podía sino causarnos extrañeza.

Para ello, el texto comienza recordando algo que ya conocemos, a saber, que el carácter de objeto se muestra como algo que desaparece. Para mostrarlo, recorre de nuevo los pasos que hemos visto, pero interpretados ahora en el sentido de que el carácter de objeto no es otro que el resultado de la enajenación o exteriorización de la conciencia misma. Una formulación muy hegeliana de aquello que había dicho Hume: que la sustancia no es más que una proyección del sujeto fuera de sí. Esto, como decíamos, parece contradecir al sentido común, pero tiene sentido si caemos en cuenta de que los objetos no pueden ser objetos sino en la medida en que la conciencia los determina como tales. Ahora bien, determinarlos como objetos no significa únicamente recortarlos del conjunto de lo dado, delimitarlos frente a la totalidad de lo

3 Me refiero a las divisiones del texto que le fueron incluidas por el editor en la primera edición y que se encuentran en el "Índice del contenido", en la edición de Johannes Hoffmeister, p. 565 y ss., y en la traducción al español de Wenceslao Roces, pero que, como no provienen del mismo Hegel, no se hallan en otras ediciones. 
que está ahí. Esa determinación implica igualmente fijarlos con respecto a la absoluta fluidez de lo real en cuanto tal. Si la realidad es un absoluto devenir temporal, radicalmente pasajero, la configuración de un objeto implica, por parte de la conciencia, que ella logre rescatarlo de ese incontenible fluir, lo que no puede hacer sino en la medida en que ella misma no sucumba a dicho devenir. La conciencia no escapa al devenir, pero, al diferenciarse a sí misma de sí misma, mantiene a la vez su propia identidad a través de él y, por decirlo así, lo domina.

Configurar un objeto significa, entonces, que la conciencia, al salir de sí misma y proyectarse fuera de sí, se despliega como el campo a la vez sincrónico y diacrónico que hace posible tal configuración. Oigamos una vez más a Hegel:

Para ella [la autoconciencia], lo negativo del objeto o su superarse a sí mismo tiene el significado positivo, o ella sabe esa nulidad del mismo, por una parte, porque ella misma se exterioriza, ya que en esa exteriorización se pone como objeto, o pone al objeto como ella misma, gracias a la unidad indivisible del ser-para-sí. Por otra parte, se encuentra allí igualmente este otro momento, que ella tiene esa exteriorización y objetividad superadas y retomadas dentro de sí, por lo tanto está cabe sí en su ser-otro como tal (Ph. 422).

Para la autoconciencia, el objeto ya no tiene el carácter de algo totalmente otro, ajeno y opuesto a ella, como lo veía Descartes, sino que se configura precisamente gracias a que ella se ha exteriorizado, ha salido de sí y se ha proyectado en lo otro, pero igualmente ha retornado a sí misma desde eso otro. La conciencia no se pierde en el mundo al exteriorizarse en él, sino que precisamente se recupera mediante ese mismo movimiento, al reconocer que el objeto en realidad no tiene más consistencia que aquella que ella le otorga.

Aquella certeza que Descartes había logrado por el camino abstracto de comenzar separando el acto de pensar de todos sus contenidos y sus formas para 
quedarse con el mero acto que, al saber de sí mismo, no puede dudar de su propia existencia, Hegel la alcanza mediante el arduo trabajo de reflexión por el cual la conciencia examina en forma ordenada y sistemática sus propias experiencias. Ahora bien, a la diversidad del método corresponde una profunda diversidad en el resultado, porque, mientras que el cogito cartesiano se muestra como una certeza abstracta ajena a toda realidad, y se sitúa en un solipsismo del cual no podrá salir sin caer en un círculo vicioso - el ya señalado círculo de Arnauld - , el saber absoluto de Hegel se muestra enriquecido por todas las anteriores experiencias que le han permitido llegar hasta él.

Se trata de comprender cómo el saber especulativo, en el cual sujeto y objeto se identifican en su misma diferencia, como en un espejo (speculum), ya que se han mostrado como momentos inseparables del verdadero saber, abre el camino a una filosofía de verdad sistemática, que comienza por comprender cómo el verdadero ser tiene la configuración del yo, para expresarlo en término de Fichte. O, tal como hemos visto que fue subtitulada por el editor la primera parte del capítulo sobre el saber absoluto, se trata de comprender "el contenido simple del sí mismo que se muestra como el ser".

Como lo señala muy bien Johannes Hoffmeister, en la "Introducción del editor" que antecede a su conocida edición de la Fenomenología, Hegel retoma la tesis de Fichte acerca del ser, concebido bajo la figura del yo, pero con dos importantes diferencias. En primer lugar, ya no se trata de una historia de la conciencia exclusivamente subjetiva, de talante cartesiano, en la cual

el saber se conquista a sí mismo y conquista sus parámetros solo a partir de sí mismo, de sus propias actividades, y no a partir de sus relaciones con la Naturaleza y con la Historia (porque, según Fichte, esa relación es solo una auto-posición del yo) $(P h$. edición de Hoffmeister XXIII).

$\mathrm{Y}$, en segundo lugar, no se lleva a cabo una mera construcción deductiva a partir de "conceptos estáticos", sino a partir de "una reflexión viviente que se 
despliega por sí misma en un universo espiritual infinitamente configurado", como dice Hoffmeister citando al poeta Novalis.

Por su parte, Jean Hyppolite, el conocido traductor al francés y comentarista de la Fenomenología, nos dice en su libro Lógica y existencia:

La cosa, el ser, no está más allá del pensamiento, y el pensamiento no es una reflexión subjetiva que sería extraña al ser. Esta lógica especulativa [la de Hegel] prolonga la lógica trascendental de Kant, exorcizando de esta el fantasma de la cosa en sí que se le aparecería a nuestra reflexión y que limitaría el saber en beneficio de una fe y de un no-saber. El saber absoluto significa la eliminación del principio de ese no-saber $(1952,3)$.

Por razones de tiempo, no me detendré a examinar la referencia que hace Hyppolite a la filosofía crítica kantiana, ni seguiré paso a paso el recuento de las figuras de la conciencia que lleva a cabo el texto de Hegel para recordarnos cómo el objeto de la conciencia fue convirtiéndose en un verdadero sí mismo. Creo que ya he indicado lo fundamental. Lo que me parece importante recalcar es cómo esta reconciliación entre la conciencia del objeto y la autoconciencia se lleva a cabo, tanto bajo la forma de lo en-sí como bajo la forma del para-sí, es decir, tanto bajo la forma de lo dado, de lo que está ahí, como bajo la forma de lo puesto, de lo establecido por la autoconciencia como su otro.

Tratemos de entender lo que esto quiere decir. Hegel hace notar que la conciliación del ser con la conciencia, o del objeto de la conciencia con la autoconciencia, se lleva a cabo, por una parte, en la Religión manifiesta, es decir en el cristianismo, y, por otra parte, en el Espíritu, es decir en el proceso de culturización de Europa. En la Religión, que tiene el carácter del para-sí por ser la autoconciencia del espíritu, esa reconciliación toma la forma del en-sí, es decir, se ofrece bajo la figura de un Dios que se ha hecho hombre; mientras que en el Espíritu, que tiene la forma de lo en-sí, dicha reconciliación se lleva a cabo bajo la forma del ser-para-sí, es decir, bajo la figura de la "autoconciencia moral" kantiana, de la cual nos dice Hegel: 
Esta sabe su saber en tanto que esencialidad absoluta, o al ser simplemente en tanto que la pura voluntad o saber; ella no es nada, a no ser esa voluntad y saber; a lo otro le corresponde solo ser inesencial, es decir, nada que sea en-sí, solo su cascarón vacío (Ph. 424).

Traduzcamos este análisis altamente conceptual a su efectuación en la historia de la conciencia. Lo que se busca mostrar es cómo la religión cristiana, en su pleno desarrollo conceptual, una vez que sus doctrinas fundamentales han podido ser comprendidas como conceptos acerca del sentido último de lo real, nos muestra cómo el ser humano, en la figura de Jesús, viene a ser la realidad objetivada de lo absoluto como sujeto; pero realiza esa objetivación bajo la figura de una realidad exterior a la conciencia. Mientras que la moralidad kantiana, por su parte, muestra cómo el sentido último del mundo se halla al interior mismo de dicha conciencia como puro deber, mientras que la realidad dada carece de todo sentido propio.

Conviene tener en cuenta que cuando Hegel analiza la religión cristiana, no utiliza el término tradicional de religión "revelada" (geoffenbarte Religion), sino que la llama "religión manifiesta" (offenbare), con lo cual pareciera estar refiriéndose ya no al cristianismo tradicional, sino a su versión luterana y liberal, elaborada por el pensamiento ilustrado, es decir, que ha pasado por la criba de la razón.

Ahora bien, aunque ambos lados, como los llama Hegel, es decir, la religión manifiesta y la moral kantiana, no se han unido todavía, deberán hacerlo:

La unión de ambos lados no se ha mostrado todavía; ella es la que cierra esta serie de configuraciones del espíritu; porque en ella el espíritu llega a saberse no solo cómo es él en sí o según su contenido absoluto, ni solo como es él para sí, según su forma carente de contenido o según el lado de la autoconciencia, sino cómo es él en y para sí (Ph. 425). 
Una vez más, tratemos de traducir estas formulaciones estrictamente conceptuales a un lenguaje más cercano a nuestra experiencia. Los dos extremos que Hegel busca reconciliar en el saber absoluto corresponden a los resultados alcanzados, por un lado, en el desarrollo de la conciencia intersubjetiva mediante la moralidad kantiana y, por el otro, en la religión manifiesta. Al primero se llega mediante la reconciliación de dos figuras contrapuestas: el hombre de acción, por una parte, que desde la precariedad de su conocimiento decide actuar aceptando la inevitable unilateralidad de su obrar y, por otra, la llamada por Hegel alma bella, figura del crítico que señala en toda acción humana esa misma unilateralidad excluyente, y que, refugiado en su crítica, se abstiene de comprometerse con la acción. La reconciliación de estas dos figuras, al reconocerse mutuamente como contrapuestas y a la vez necesarias, se lleva a cabo en el seno del Estado de derecho, y constituye la forma subjetiva del ciudadano que comprende cómo el sentido de su existencia se lleva cabo en la configuración histórica de tal sociedad.

Por su parte, el desarrollo conceptual de la religión cristiana o religión manifiesta presenta en sus doctrinas de manera objetiva cómo la comunidad creyente configura la plena realización de esa misma sociedad en su devenir histórico. De ahí que reconciliar ambos resultados venga a significar la superación del cristianismo, en el fuerte sentido que el término "superar" (Aufheben) tiene para Hegel. Se trata de suprimir la conciencia imperfecta que ve en una figura histórica del pasado, en Jesús, y en su vida, pasión y muerte, una figura externa a la conciencia, y no la manifestación objetivada de que el sentido último de la realidad, el verdadero Dios, lo constituye la humanidad como comunidad que, a lo largo de su historia, busca la realización de un verdadero Estado de derecho. Pero esa superación es también una elevación, ya que la nueva figura religiosa, configurada ahora por la comunidad creyente, le quita a la doctrina religiosa su carácter de exterioridad y facticidad, para convertirla en la tarea que deberá orientar nuestro quehacer. Y, a su vez, esa elevación significa una conservación de la religión cristiana y de la realidad moral reconciliada con ella, ya que una y otra cumplen, cada una a su manera, la tarea de llevar al ciudadano común a la comprensión práctica de sus funciones. 
Con ello hemos señalado el segundo aspecto del saber absoluto, a saber, su relación con la religión. Creo que el sentido de la superación de la religión cristiana, considerada como religión manifiesta, nos quiere decir que, mientras que todos los dogmas religiosos pueden ser comprendidos como formulaciones de conceptos fundamentales hechas en un lenguaje propio de la imaginación, pero no por ello erróneo, hay uno en particular que brilla por su ausencia: la doctrina de la resurrección personal más allá de la muerte, formulada de manera drástica por el llamado Símbolo de los Apóstoles como la "resurrección de la carne". A esta Hegel no le dedica ninguna consideración particular; para él, el sentido de la vida humana es inmanente, se halla en el conocimiento o en la Ciencia, es decir, en la filosofía, y en la historia, es decir, en el servicio a la humanidad en su devenir histórico.

Hay dos argumentos más en la Fenomenología que parecen confirmar esta conclusión acerca de la religión que hemos derivado del concepto de saber absoluto, argumentos a los cuales solo voy a referirme en forma muy somera.

El primero lo encontramos al comienzo del capítulo sobre la Religión, cuando Hegel hace un recuento retrospectivo para mostrar cómo, en el camino de las experiencias de la conciencia, varias de las figuras tenían ya un carácter religioso: son aquellas en las cuales el sentido de la conciencia se halla situado en un más allá inalcanzable. Estas figuras se hallan presentes en todos los momentos recorridos, menos en uno. Para la conciencia, se trata del entendimiento y su mundo suprasensible o interior, es decir, el mundo de la leyes; para la autoconciencia, es la conciencia desventurada, figura del creyente que busca su sentido en un absoluto más allá; e igualmente en el espíritu se nos hace presente la religión en cada una de sus etapas: la religión del mundo subterráneo para los griegos, la fe que se contrapone a la Ilustración en el proceso de la cultura, y finalmente en la moral kantiana.

Hay, entonces, un solo momento en el cual, nos dice Hegel, no hay religión, y ese momento es la razón: esta, así como las figuras que le son propias, dice Hegel, "no tienen religión alguna, porque la autoconciencia de las mismas se sabe o se busca en el presente inmediato" (Ph.443). En otras palabras, para la 
razón, por su carácter hegemónico, no puede haber nada que se halle más allá de ella, que no esté sometido a las condiciones de su finitud; lección aprendida sin duda de Spinoza.

Pues bien, si nos fijamos ahora en la estructura general de la obra, vemos que los tres momentos iniciales: conciencia, autoconciencia y razón, se corresponden con los tres momentos finales: espíritu, religión y saber absoluto. Lo cual quiere decir que, mientras que el espíritu se corresponde con la conciencia y la religión con la autoconciencia, la correspondencia del saber absoluto es precisamente con la razón, es decir, con aquel momento del cual nos dice Hegel claramente que en él no hay religión. En otras palabras, para el saber absoluto no hay ninguna realidad originariamente trascendente, un Dios que pueda irrumpir, por así decirlo, desde fuera y revelarse. En este preciso sentido, para el saber absoluto no hay religión, no hay una trascendencia originaria, un más allá absoluto.

Por otra parte, hay un argumento adicional que encontramos en la bien conocida figura de la lucha por el reconocimiento, donde las dos conciencias del amo y del siervo se traban en una confrontación a muerte. Allí nos dice el texto que el siervo se halla sometido al señor por el temor a la muerte, y que, mientras ese temor no haya sido superado, no podrá liberarse definitivamente de su servidumbre. Ahora bien, ¿cómo se da esa liberación del miedo a la muerte, al que Hegel señala como "el señor absoluto"? (Ph. 114). Esa liberación se lleva a cabo mediante el trabajo: "Mediante el trabajo — dice Hegel—, ella [la conciencia del siervo] retorna a sí misma" ( $P h .114$ ); y lo hace gracias a su doble significación; porque, al configurar el mundo, la conciencia trabajadora, en su misma singularidad, sale de sí misma,

[y] la relación negativa con el objeto llega a ser la forma del mismo y algo permanente; precisamente porque, para el trabajador, el objeto tiene autosuficiencia. [...] La conciencia trabajadora llega por ese medio a la intuición del ser autosuficiente como [a la intuición] de sí misma (Ph. 115). 
Así, al configurar el mundo, al transformarlo a su imagen y semejanza, la conciencia se objetiva, adquiere permanencia. Pero esa acción de configurar el mundo tiene, por otra parte, un carácter negativo, porque con ella se destruye el miedo a la muerte. ¿Cómo? El texto nos ofrece una formulación a mi parecer no muy clara, pero que merece toda nuestra atención, ya que en ella se expresa nada menos que la forma de superar el miedo a la muerte, al que la religión cristiana contrapone precisamente la doctrina de la resurrección personal:

Pero el formar [Formieren] no tiene únicamente este significado positivo de que la conciencia servil, como puro ser-para-sí, se vuelva ente ${ }^{4}$; sino también el negativo en contra de su primer momento, del temor. Porque, en el formar de la cosa, la propia negatividad, su ser-para-sí, solo se le vuelve objeto porque supera la forma contrapuesta entitativa ${ }^{5}$. Pero eso negativo objetivo es precisamente la esencia ajena ante la cual se había estremecido. Pero ahora ella destruye eso negativo extraño, se pone como tal en el elemento del permanecer; y por ello se vuelve para sí misma, un ente para sí (Ph. 115).

Hegel identifica el miedo a la muerte con la negatividad propia a lo otro de la conciencia, con el carácter natural de lo simplemente dado. La muerte se halla presente como la negación radical de nuestro ser para sí, como la suprema exterioridad, y en ello parece hacer eco a las reflexiones de Spinoza, para quien la negación de algo existente viene siempre de algo exterior. Y será precisamente el trabajo el que le suprima a esa exterioridad su carácter amenazante, de modo que en esa objetividad la conciencia solo se encuentre a sí misma. En otras palabras, el miedo a la muerte será superado en la medida en que el ser humano, habiéndole dado a la realidad su propia forma, habiendo transformado la realidad a su imagen y semejanza, se descubra a sí mismo

4 Seiendes: "lo que está siendo", "ente".

5 De nuevo tenemos el gerundio seiend, pero ahora como adjetivo. 
en ella. "Trabajando — dice Valls Plana — [el siervo] destruye la naturalidad del objeto, esa naturalidad de la cual no quiso desprenderse para afirmarse solamente como autoconciencia superior a la naturaleza" (1994, p. 137).

Con ello creo haber argumentado de manera suficiente las dos tesis que me había propuesto sustentar en este escrito. Primera tesis: el saber absoluto es tal precisamente porque en él, como resultado de la historia del pensamiento, hemos llegado a comprender que la realidad solo puede ser concebida como un yo, como un proceso que se mantiene idéntico consigo precisamente gracias a la conciencia que, recuperando su pasado y proyectando su futuro, logra que ese devenir incontenible adquiera sentido. Este saber es absoluto en el sentido de que se fundamenta a sí mismo, ya que es un saber del objeto como idéntico con el sujeto, o un saber en el que sujeto y objeto configuran una identidad en su misma diferencia. Segunda tesis: ese mismo saber absoluto significa la superación definitiva de la religión, bajo la forma de religión manifiesta, porque el sentido de la vida humana no se halla en un más allá incomprensible o inaccesible, sino en la trascendencia del individuo en su comunidad, gracias a su participación activa en los procesos históricos. 